FOCUSED DISCUSSION

Editor's Introduction

\title{
Frankenstein in Lilliput: Science at the Nanoscale
}

\author{
Isaac Record*
}

Since Robert Hooke published Micrographia, scientists have been expanding the boundaries of science to new scales, giving rise to questions about epistemology and ontology and challenging perceptions of objectivity, life, and artifact. Recent developments in areas such as nanotechnology and synthetic life have not only pushed these boundaries, but have called their very existence into question. In this issue, Spontaneous Generations examines science at the nanoscale from ten perspectives.

In the first peer-reviewed contribution, Jaipreet Virdi examines the epistemological gap between theory and practice in the burgeoning field of nanomedicine. By taking seriously the demonstrable risks of nanomedicine (but leaving aside apocalyptic visions of "grey goo"), Virdi argues that we do not need to halt the development of nanomedicine in order to forestall disaster. As long as nanomedicine develops gradually enough to allow our existing infrastructure and institutions to adapt together with the science, ethical considerations should come prior to, but within striking distance of, science fact.

Ethics is about more than guiding practices, argues Joachim Schummer in an invited contribution. Science can be popularized by its ethics-indeed, engineering ethics is often propaganda for emerging technology, even if not by design. Schummer describes three popularization traps for ethicists to avoid, concluding that ethicists need to be self-reflective both to avoid these popularization traps and to make ethics a more fruitful advisory discipline. And ethicists need to engage directly with the scientists and engineers actually doing the work at the cutting edge, not just with other ethicists and policymakers.

In her peer-reviewed contribution, Kasi Jackson considers the relationship between science and society, an issue Stephen Bocking discussed in this journal's last Focused Discussion. From the point of view of science policy, Jackson shows that institutional changes meant to encourage diversity can result in more reflective practices, encouraging scientists to assess their assumptions critically. Jackson goes on to characterize the relationship between science and society from the perspective of fiction; the mad scientist of disaster fiction can contaminate our views of both science and scientists. But fiction can also rehabilitate public opinion.

\footnotetext{
* Isaac Record is a PhD candidate at the Institute for the History and Philosophy of Science at the University of Toronto. His research is focused on the question of how the adoption and use of scientific instruments-such as the computer-have constrained and shaped scientific practice.
} 
Moreover, fiction enables us to explore possible futures without the risks, as Colin Milburn argues. Today's nanoscale experiments already aim for the imagined future in which nanotechnology reshapes our lives. We build virtual worlds for our nanocreations in order to experience what we cannot experience through our own senses. Virtual worlds-online worlds-are already prime sites for social research. Can these worlds also shield us from the potential dangers of nanotechnology-or even provide the bridge to an integrated future of peaceful coexistence with robots?

Whatever happens in the virtual world, much of what we say about nanotechnology and synthetic life is mediated by metaphors. Joe Pitt offers an exploration of the rhetorical and heuristic role of metaphor in nanotechnology. For Pitt, metaphors like 'fat' or 'sticky' fingers are a way of sketching the world of possibilities at the nanoscale. We must give reasonable attention to the epistemic value of metaphor. Two metaphors of particular interest are the computer program or information system metaphor and the machine metaphor. Matthew Kearnes argues that when nanotechnicians use the 'systems' metaphor, it changes their understanding of the ontology: "all that 'is' is cast in informational terms" so that "biological and physical life can be manipulated as if it were information" (p. 104). Natasha Myers explains how, for some practitioners, conceptions of "life itself" are shifting to machine rather than computer program metaphors. "These are investigators who, in their productive application of the machine as a metaphor, have been successful in turning molecules into visible, tangible, and workable objects," Myers argues, but moreover, metaphor "is an act of conjuring that relies heavily on imagination and handiwork" (p. 118).

According to Ana Viseu, "monsters are also not accidental or innocent: their creation requires sustained work, their existence has effects. Thus, to understand how Frankenstein came to be in Lilliput, the theme of this special edition, it is crucial to examine how monsters are constructed and how they do things in the world" (p. 122). Viseu presents conclusions based on an ethnography of two conferences, focusing on how practices discipline nano by defining it. Nano, according to practitioners at these conferences, is about scale, hype, science vs. technology, and old vs. new. It conceives itself as 'different' and therefore in need of a new ethos and new praxis.

In his contribution, Otávio Bueno is concerned with visual evidence at the nanoscale: nanotechnology almost always involves "the production of images that are supposed to offer evidence that certain relations hold among the nanoscale objects that are studied" (p. 133). The experience of these images is crucial to knowing what researchers are said to know about the nanoscale objects they manipulate, he argues. But what are the images of? In practice, there is a gap between describing an image and describing the sample, and this challenges traditional epistemology. 
Scientific practice at the nanoscale offers a new perspective on another perennial problem in the philosophy of science: scale. Traditional philosophy of science has the intuition that the relationship between scales is a mereological one: continuum mechanics just is a generalisation of molecular dynamics. Eric Winsberg, a philosopher concerned with models and simulations, looks at the "multiscale" approaches to modeling cracks in solid structures on the order of one micron in size. Scientists use multiscale approaches when practical concerns about computability make it impossible to produce results at the lower level. In their implementations, there is feedback between different levels of simulation, which-contra tradition-Winsberg argues is essential to making the model work.

We hope that this focused discussion section of the second issue of Spontaneous Generations makes a modest contribution to the growing scholarship on science at the nanoscale. We welcome comments and responses at hapsat.society@utoronto.ca or through the journal's online comment or submission system. We will be pleased to publish these contributions with our next issue.

ISAAC RECORD

IHPST, University of Toronto

91 Charles St. West

Toronto, ON

Canada M5S 1K7

isaac.record@utoronto.ca 